Article

\title{
Esterification of Fatty Acids with Short-Chain Alcohols over Commercial Acid Clays in a Semi-Continuous Reactor
}

\author{
Soumaya Bouguerra Neji, Mahmoud Trabelsi * and Mohamed H. Frikha \\ Laboratory of Applied Chemistry: Heterocycles, Fats and Polymers, Faculté des Sciences de Sfax, \\ Route de Soukra Km 3.5, 3038-Sfax, Tunisia; E-Mails: soumaya5555@ yahoo.fr (S.B.N.); \\ mohamedhedi.frikha@gmail.com (M.H.F.) \\ * Author to whom correspondence should be addressed; E-Mail: Mah.Trabelsi@ fss.rnu.tn; \\ Tel.: +21-698-615-302; Fax: +21-674-676-606.
}

Received: 18 September 2009 / Accepted: 6 November 2009 / Published: 19 November 2009

\begin{abstract}
Production of fatty acid esters from stearic, oleic, and palmitic acids and short-chain alcohols (methanol, ethanol, propanol, and butanol) for the production of biodiesel was investigated in this work. A series of montmorillonite-based clays catalysts (KSF, KSF/0, KP10, and K10) were used as acidic catalysts. The influence of the specific surface area and the acidity of the catalysts on the esterification rate were investigated. The best catalytic activities were obtained with KSF/0 catalyst. The esterification reaction has been carried out efficiently in a semi-continuous reactor at $150^{\circ} \mathrm{C}$ temperature higher than the boiling points of water and alcohol. The reactor used enabled the continuous removal of water and esterification with hydrated alcohol (ethanol 95\%) without affecting the original activity of the clay.
\end{abstract}

Keywords: esterification; montmorillonite; semi-continuous reactor; fatty acid; hydrated alcohol

\section{Introduction}

The fatty acid esters constitute a group of useful chemical intermediates in the synthesis of several products such as amides, sulfonates and fatty alcohols. These compounds can be applied as solvents, spreading or softening agents in polymers. They are also used in the textile, cosmetic and rubber industries [1]. Recently, long-chain fatty acid alkyl esters have spurred a great deal of interest, in the synthesis of biodiesel [2]. 
Actually, the most attractive biofuel is represented by biodiesel, which is a mixture of fatty acid methyl or ethyl esters, produced by a transesterification reaction performed on vegetable oils with methanol or ethanol. The catalysts that are more widely used, and which are the most effective in this step of the process, are sodium and potassium hydroxide [3,4]. However, some severe drawbacks must be accounted for in this case: the presence of moisture and free acidity that strongly influences the process performance and economics. In fact, both water and free fatty acids (FFA) rapidly react with the catalyst, consuming it and giving way to long-chain soaps whose tenside properties do not allow an efficient separation of the pure glycerol byproduct. In the case of oil with a high content of FFA, like usually happens in waste materials, a pretreatment esterification step must be considered as mandatory in order to eliminate the free acidity that must be reduced below 1\%. Esterification of FFA to alkyl esters in the presence of an acidic catalyst is a route to improving the use of high FFA oils in biodiesel production.

Esterification is normally carried out in the homogenous phase in the presence of acid catalysts such as sulfuric acid, hydrochloric acid and $p$-toluenesulfonic acid ( $p$-TsOH). The use of such catalysts has many inconvenients that include corrosion, loss of catalyst and environmental problems $[5,6]$.

Efforts have therefore been made to develop eco-friendly heterogeneous catalysts for the synthesis of fatty acid esters. The most popular solid acids catalyst used to produce esters were ion-exchange organic resins, such as Amberlyst-15 [7,8], zeolites [9-11], and silica-supported heteropoly acids $[12,13]$. Nevertheless, they have shown limitations in applicability for catalyzing esterification due to low thermal stability (Amberlyst- $15<140{ }^{\circ} \mathrm{C}$ ), mass transfer resistance (zeolites) [14,15], or loss of active acid sites in the presence of a polar medium (HPA/silica) [13].

Clay catalysts have received considerable attention in different organic syntheses due to their environmental compatibility, low cost, high selectivity, thermal stability and reusability [16]. Acid-activated clays are one of the most widely studied solid acid catalysts for many organic transformations such as alkylation [17, 18], condensation [19], dimerisation [20], isomerisation [21], ether formation [22] and transesterification reactions [23], but they are rarely used as catalyst in esterification reactions.

The esterification of fatty acids is usually carried out by short chain anhydrous alcohols having low boiling points. The water formation during the reaction remains the principal handicap to develop suitable synthesis processes for fatty esters. The elimination of this water using azeotropic solvents (i.e., xylene) or using large excess of alcohol was the major solutions applied to achieve good fatty ester yields.

In the present work, we report on the esterification of stearic, palmitic and oleic acids with short chain alcohols (methanol, ethanol, propanol and butanol) over acidic clays. The reaction was carried out under atmospheric pressure in a semi-continuous reactor which can operate at high temperatures $\left(150{ }^{\circ} \mathrm{C}\right)$ above the boiling point of the alcohol and water and with a continuous constant flow of alcohol being added to the reaction mixture. Under these reaction conditions, the fatty acid amount was in excess compared to that of alcohol. The formed water was eliminated during the reaction time enhancing thus the fatty ester production. A variety of montmorillonite catalysts (KSF, KSF/0, KP10 and K10) have been tested. The possibility of esterifying the fatty acids with hydrated alcohol (95\% ethanol) was also investigated. 


\section{Experimental Section}

\subsection{Materials}

The four commercials clays (Montmorillonite KSF/0 clay, Montmorillonite KSF clay, Montmorillonite KP10 clay, and Montmorillonite K10 clay) used as catalysts in this study were purchased from Fluka and used as received without further treatment. The relevant physico-chemical properties of the catalysts used are given in Table 1 [24]. Stearic acid, palmitic acid and oleic acid were purchased from Sigma Aldrich. All the other chemical reagents and solvents such as sodium hydroxide pellets (97\%), hexane, methanol, propanol, 1-butanol, 2-butanol and absolute ethanol were purchased from Prolabo, ethanol (95\%) was produced by Chemi-pharma.

Table 1. Some characteristic data of the investigated catalysts [24].

\begin{tabular}{|c|c|c|c|c|c|}
\hline \multirow{3}{*}{ Catalysts } & \multicolumn{2}{|c|}{ Textural characteristics } & \multicolumn{3}{|c|}{ Acidity } \\
\hline & \multirow{2}{*}{$\begin{array}{c}\text { Specific } \\
\text { surface }\left(\mathrm{m}^{2} / \mathrm{g}\right)\end{array}$} & \multirow{2}{*}{$\begin{array}{l}\text { Average pore } \\
\text { diameter }(\AA)\end{array}$} & \multirow{2}{*}{ pH } & \multicolumn{2}{|c|}{ Surface $\operatorname{acidity}\left(\mathrm{mmol} \mathrm{g}^{-1}\right)$} \\
\hline & & & & Brönsted & Lewis \\
\hline $\mathrm{KSF} / 0$ & 117 & 74 & 1.3 & 1.03 & 0.20 \\
\hline KSF & 30 & 50 & 1.5 & 0.59 & 0.15 \\
\hline KP10 & 169 & 71 & 1.8 & 0.49 & 0.09 \\
\hline K10 & 249 & 56 & 4.5 & 0.33 & 0.29 \\
\hline
\end{tabular}

\subsection{General reaction procedure}

Catalysis tests were carried out in a semi-continuous reactor [25-27] composed of a three-neck flask $(100 \mathrm{~mL})$ equipped with a water-cooler condenser, a thermometer and a magnetic stirrer (Figure 1).

Figure 1. Schematic representation of the semi-continuous reactor used for this study.

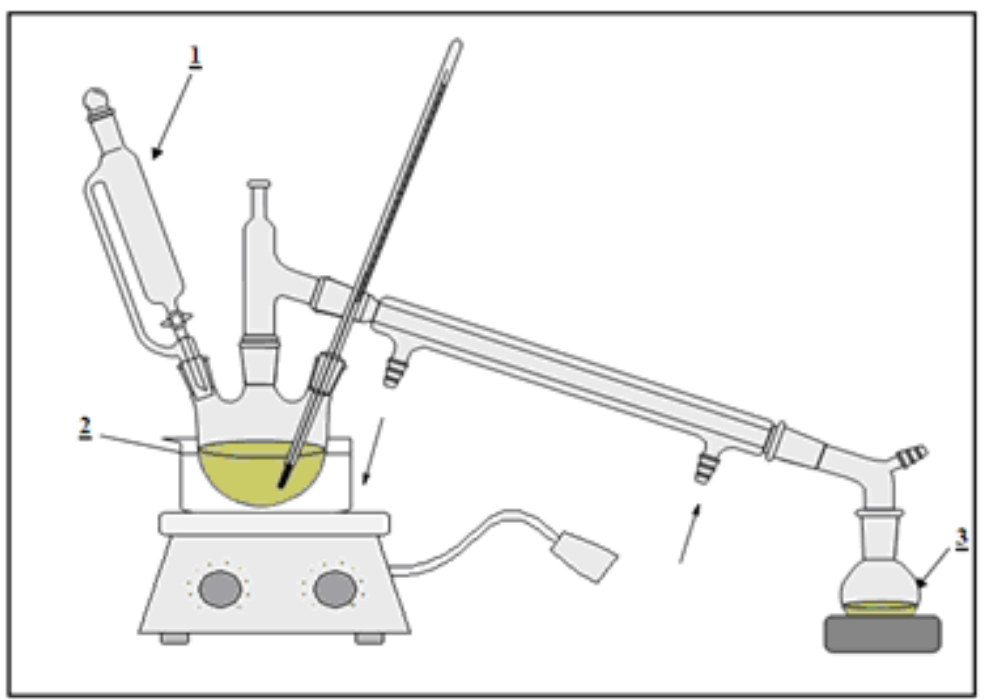

1: alcohol; 2: fatty acid + clay; 3: alcohol + water. 
Two grams of fatty acid (stearic, oleic or palmitic acid) was introduced into the reactor and then heated at $150{ }^{\circ} \mathrm{C}$. After that, $350 \mathrm{~mL}$ of absolute ethanol was added dropwise during the reaction time (300 min) with a constant flow of $2 \times 10^{-2} \mathrm{~mol} \mathrm{~min}^{-1}$. The alcohol, as well as the produced water were continuously removed from the reaction medium after condensation and recovered at the exit of the reactor. When the first drop of ethanol was recovered in the recovery flask, the catalyst was immediately introduced into the reaction mixture. This moment was considered as the starting time of the reaction (equilibrium startup mode) [26, 27]. Samples were withdrawn at different time intervals to determine the remaining amount of fatty acid by titration with a sodium hydroxide solution $\left(0.017 \mathrm{~mol} \mathrm{~L}^{-1}\right)$. The conversion of fatty acid was calculated by the following formula [28]:

$$
\mathrm{R}(\%)=\frac{\mathrm{a}_{\mathrm{i}}-\mathrm{a}_{\mathrm{t}}}{\mathrm{a}_{\mathrm{i}}} \cdot(100)
$$

where $a_{i}$ is the initial acidity of the mixture and $a_{t}$ is the acidity at a time " $t$ ".

\subsection{Effect of catalyst loading}

To study the effect of catalyst loading, $2 \mathrm{~g}$ of stearic acid was esterified with diverse catalyst loadings varying from $0.02 \mathrm{~g}$ to $0.4 \mathrm{~g}$, which correspond to a mass ratio of $0.01-0.2 \mathrm{w} / \mathrm{w}$. All experiments were realised with montmorillonite $\mathrm{KSF} / 0$ at $150{ }^{\circ} \mathrm{C}$ during $4 \mathrm{~h}$.

\subsection{Esterification with others alcohols}

In this section, the effect of the length of the alcohol carbon chain and the influence of the location of the alcoholic group were studied. $2 \mathrm{~g}$ of stearic acid was esterified in the presence of $0.2 \mathrm{~g}$ of montmorillonite $\mathrm{KSF} / 0\left(\mathrm{C}_{\mathrm{c}}=0.1 \mathrm{w} / \mathrm{w}\right)$ at $150{ }^{\circ} \mathrm{C}$ during $4 \mathrm{~h}$ using different alcohols. To have the same flow of alcohol $\left(2 \times 10^{-2} \mathrm{~mol} \mathrm{~min}^{-1}\right)$ and therefore a constant molar ratio acid/alcohol, the reactor was charged with different alcohol volumes: 195, 280, 360, 445 and $445 \mathrm{~mL}$ for methanol, ethanol, propanol, 1-butanol and 2-butanol, respectively.

\subsection{Catalyst regeneration}

The clay was separated from the reaction mixture by filtration, washed with hexane, dried at $80{ }^{\circ} \mathrm{C}$ for $24 \mathrm{~h}$, and reused to study its activity for the esterification reaction carried out in both conventional and semi-continuous reactors. The conventional reactor was composed of a two-neck flask (100 $\mathrm{mL})$ equipped with a vapor condenser and a thermometer. Two $\mathrm{g}$ of stearic acid and $50 \mathrm{~mL}$ of ethanol were charged in the reactor and heated at the boiling point of alcohol $\left(78^{\circ} \mathrm{C}\right)$. The reaction medium was stirred vigorously with a magnetic stirrer. The catalyst was added $(0.1 \mathrm{w} / \mathrm{w})$ when the temperature of the reaction mixture reached a constant value. The semi-continuous reactor is described above.

\section{Results and Discussion}

\subsection{Catalytic activity of acid clays}

A variety of montmorillonite catalysts $\mathrm{KSF}, \mathrm{KSF} / 0, \mathrm{KP} 10$ and $\mathrm{K} 10$ have been investigated in the esterification of stearic acid with ethanol. Figure 2 shows the conversion profiles relative to the 
reaction times at $150{ }^{\circ} \mathrm{C}$ over the studied catalysts $(0.1 \mathrm{w} / \mathrm{w})$. It can be noticed that the reaction rate increases according to the following order: KSF/0 $>\mathrm{KSF}>\mathrm{KP} 10>\mathrm{K} 10$. No correlation was found between surface area, average pore diameter with the esterification activity of the catalysts. Indeed, K10 with the higher surface area $\left(249 \mathrm{~m}^{2} / \mathrm{g}\right)$ leads to the slower reaction rate. This result is in agreement with the report of Pushpaletha et al. on the correlation between surface properties and catalytic activity of montmorillonite catalysts [29]. Except for the KP10 catalyst sample, it seems that the catalytic activity increases with the total surface acidity. Besides, a decrease of clay $\mathrm{pH}$ leads to an increase of esterification rate, for all catalysts (Table 1). A total conversion of acid was obtained after 240 min with KSF/0 which has the lowest $\mathrm{pH}$ value and the highest Brönsted acidity. At the same time, the yield of esterification was about $85 \%$ and $80 \%$ when operating with KSF and KP10, respectively; whereas it was lower than $60 \%$ in the $\mathrm{K} 10$ case.

Figure 2. Conversion profiles of the esterification of stearic acid with ethanol over different acidic clay catalysts $\left(\mathrm{T}=150{ }^{\circ} \mathrm{C}\right.$ and $\left.0.1 \mathrm{w} / \mathrm{w}\right)$.

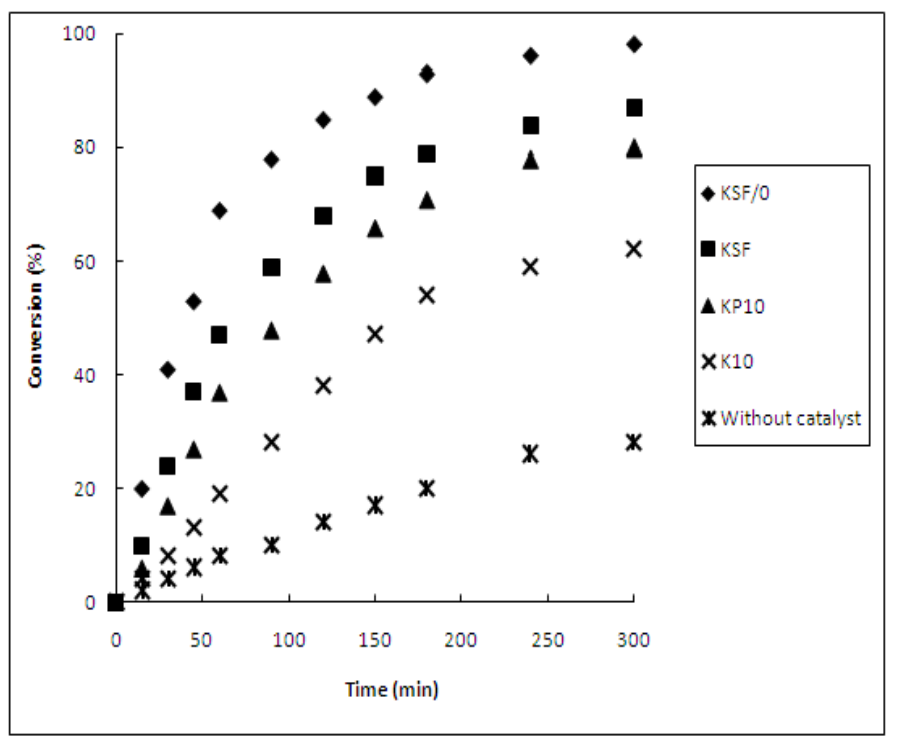

Generally, the homogenous catalysts (sulphuric acid, $p$-toluenesulfonic acid) were better than the heterogeneous catalysts, displaying faster kinetics and higher reactivity. However, the KSF/0 clay allows a conversion higher than $70 \%$ of the initial fatty acid in $1 \mathrm{~h}$ and $93 \%$ after $3 \mathrm{~h}$. Hanh et al., have obtained the same ethyl oleate conversion after $1 \mathrm{~h}$ stirring and the same ethyl stearate conversion after $3 \mathrm{~h}$ ultrasound irradiation using sulphuric acid as catalyst [30]. The esterification over acid clays proceed at lower temperature than transesterification. In fact, the transesterification using heterogeneous catalysts requires usually temperature in excess of $200{ }^{\circ} \mathrm{C}$ to achieve $>90 \%$ conversion within the timescale of the experiments [31].

\subsection{Effect of catalyst loading}

The effect of the clay loading on conversion of stearic acid with ethanol, at $150{ }^{\circ} \mathrm{C}$, for $4 \mathrm{~h}$, over $\mathrm{KSF} / 0$ as catalyst was studied. Figure 3 presents the fatty acid conversion as a function of catalyst concentration $\mathrm{C}_{c}$ (where $\mathrm{C}_{\mathrm{c}}$ is the weight of catalyst/initial weight of fatty acid) which shows two 
different domains. In the first part, the ester conversion increases proportionally with the $\mathrm{C}_{c}$, whereas it is found to be independent of the catalyst concentration above $0.1 \mathrm{w} / \mathrm{w}$ ( $97 \%$ of fatty acid was converted). The results obtained suggest that the initial activity increases with total number of active catalytic available sites.

Figure 3. Conversion (\%) of esterification of stearic acid with ethanol over KSF/0 catalyst versus catalyst concentration at $150{ }^{\circ} \mathrm{C}$.

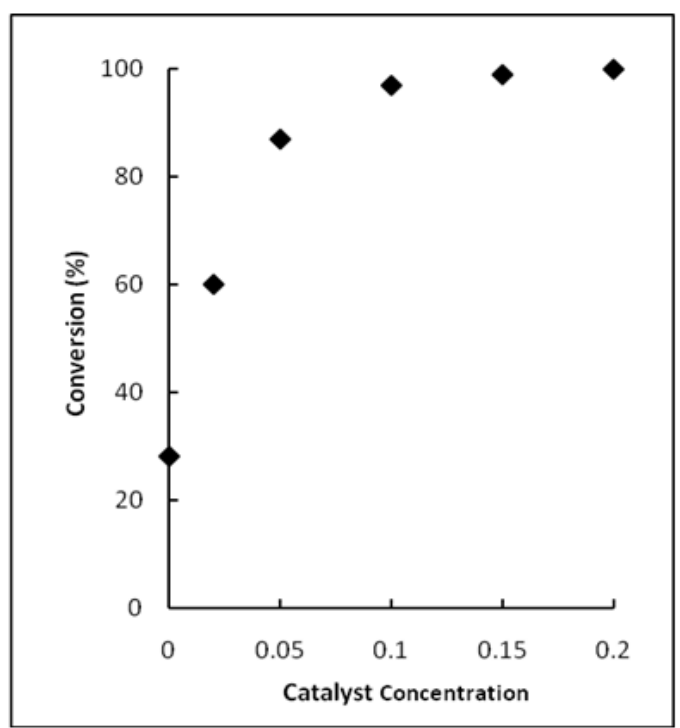

\subsection{Esterification of other fatty acids}

Montmorillonite KSF/0 was also used as catalyst in the esterification of oleic and palmitic acids with ethanol. Figure 4 shows the conversion of fatty acid as a function of time. Although there were no significant differences in the length chains of the fatty acids, a slight increase on the conversion was observed for the stearic acid (C18). These results are in agreement with those obtained on the esterification of palmitic, stearic, and oleic acids with methanol using PVA-SSA40 as catalyst carried out by Caetano et al. [32].

Figure 4. Conversion profiles of the esterification of stearic, palmitic and oleic acid with ethanol over $0.1 \mathrm{w} / \mathrm{w} \mathrm{KSF} / 0$ catalyst at $150{ }^{\circ} \mathrm{C}$.

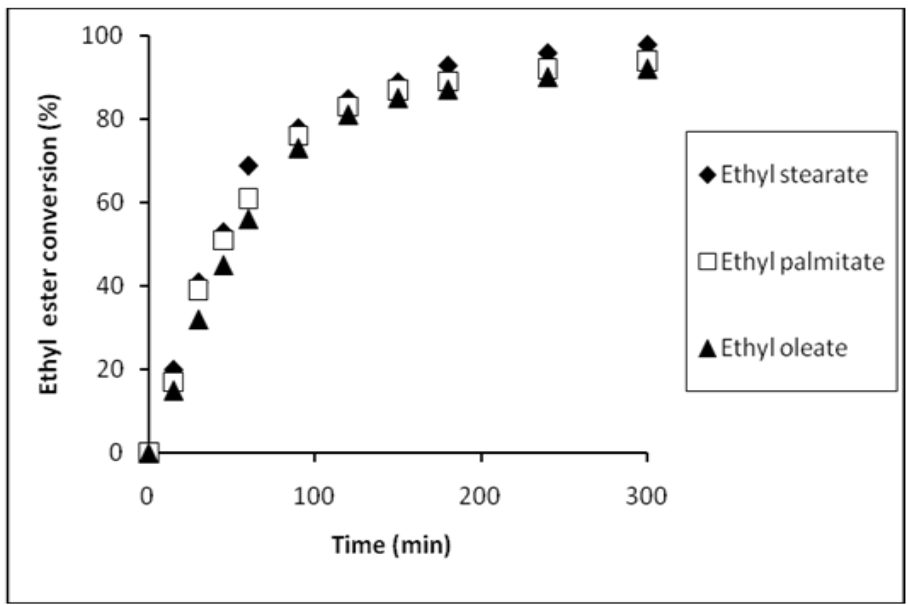




\subsection{Effect of the length of the alcohol's carbon chain}

To compare the effect of the alcohol carbon chain on the reaction yield, four different alcohols have been used: methanol, ethanol, propanol and butanol. The operational conditions were similar for all experiments. The reaction was carried out using pure stearic acid and montmorillonite KSF/0 as catalyst. It seems that the yield of esterification reactions is strongly dependent to the physical properties of the alcohol used (Table 2). Butanol, has the higher boiling point temperature, thus it evaporates at $150{ }^{\circ} \mathrm{C}$ but at a lower rate than the other alcohols. Consequently, the instantaneous residual amount of butanol exceeded that of propanol, which was also higher than that of ethanol. The esterification with butanol will therefore be favored by the presence of a greater amount of alcohol in the reaction mixture.

Table 2. Esterification yields of stearic acid with different alcohols over KSF/0 catalyst $(0.1 \mathrm{w} / \mathrm{w})$ at $150^{\circ} \mathrm{C}$.

\begin{tabular}{|c|c|c|c|}
\hline Fatty acid & Alcohol & Boiling point & R (\%) \\
\hline Stearic acid & methanol & $65^{\circ} \mathrm{C}$ & 96 \\
Stearic acid & ethanol & $78.5^{\circ} \mathrm{C}$ & 97 \\
Stearic acid & propanol & $97.5^{\circ} \mathrm{C}$ & 98.5 \\
Stearic acid & butanol & $117.5^{\circ} \mathrm{C}$ & 99.9 \\
Stearic acid & 2-butanol & $114.7^{\circ} \mathrm{C}$ & 40 \\
\hline
\end{tabular}

To evaluate the influence of the location of the alcoholic group on the esterification yield, 2-butanol was also used. A net increase can be seen in the final conversion of 1-butanol compared to 2-butanol (Table 2). This effect might be due to a steric effect on the secondary alcohol [33]. However, the same yield (40\%) was obtained by Hanh et al. after $5 \mathrm{~h}$ of ultrasound irradiation [30].

\subsection{Esterification with hydrated alcohol}

The esterification reaction is usually carried out by anhydrous alcohols to increase the conversion rate of fatty acids. Indeed, the presence of water promotes the reverse reaction. In this study, we suggested the use of the low cost industrial grade ethanol (95\%), as it would be beneficial to be able to conduct this reaction under certain water-containing conditions without influencing the original activity. Our results (Table 3) show high yields of esterification in the presence of ethanol $95 \%$ for all fatty acids studied. This result is very promising compared to the one found in a former study [33]. Indeed, the esterification of oleic acid with ethanol $96 \%$ reduces the esterification yield from $15 \%$ to only $4 \%$ after 150 min reaction. Further, the recovered mixture (ethanol+ water) can be reused without substantial loss of the conversion yield (97\% after one cycle and $95 \%$ after two cycles).

The esterification in semi-continuous reactor leads not only to the continuous removal of the produced water from the reactor, but also the esterification with hydrated alcohol without any decrease in the final conversion. 
Table 3. Effect of water contained in ethanol: esterification of stearic, oleic, and palmitic acid with ethanol 99 and ethanol 95.

\begin{tabular}{ccc}
\hline Fatty acid & alcohol & R (\%) \\
\hline Stearic acid & Ethanol 99 & 97 \\
Stearic acid & Ethanol 99* & 97 \\
Stearic acid & Ethanol 99** & 95 \\
Stearic acid & Ethanol 95 & 97 \\
Oleic acid & Ethanol 99 & 92 \\
Oleic acid & Ethanol 95 & 92 \\
Palmitic acid & Ethanol 99 & 94 \\
Palmitic acid & Ethanol 95 & 94 \\
\hline & $*$ recovered ethanol after one cycle \\
& $* *$ recovered ethanol after two cycles
\end{tabular}

\subsection{Catalyst stability and reusability}

The reusability of solid catalysts is one of their main advantages compared to liquid homogeneous catalysts. To evaluate this characteristic for the clay catalysts, the esterification reactions of stearic acid with ethanol were investigated by running consecutive reaction cycles under the same reaction conditions. The yields of the esterification reaction during four cycles and those obtained with a conventional reactor (according to the general procedure described in the Experimental section) are presented in Figure 5.

Figure 5. Catalytic activity of the esterification of stearic acid with ethanol, in four consecutive experiments in the conventional and semi-continuous reactor.

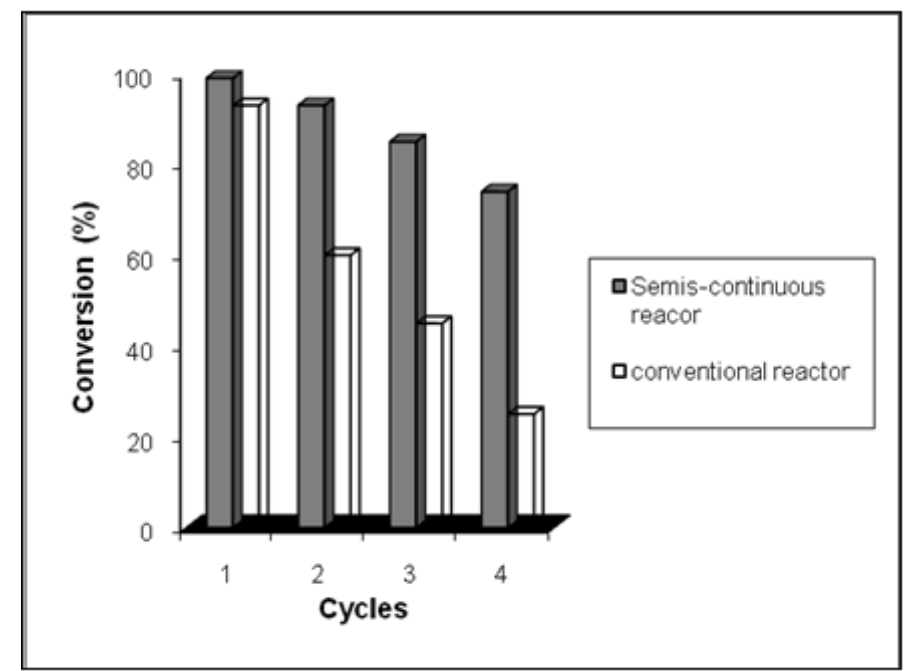

With the presence of excess alcohol, it was reported that clays lose their catalytic activities after one cycle of reaction and should be re-impregnated by acid for use in a second cycle of reaction [34]. This same phenomenon was observed in a conventional reactor under reflux in the presence of ethanol in excess (Figure 5). The esterification, with reduced amounts of alcohol, in a semi-continuous reactor, 
limits the rapid release of acidity and enables the retention of the catalytic activity of the catalyst solid for several cycles of reaction ( $84 \%$ after three cycles).

\section{Conclusions}

The esterification of fatty acid with short chain alcohols over acid clays was efficiently carried out in a semi-continuous reactor. The montmorillonite $\mathrm{KSF} / 0$ has proven to be the most effective of the tested catalysts. Besides the catalytic activity of the catalyst type, the influence of various reaction parameters, such as catalyst loading and type of alcohol, was studied. The semi-continuous reactor operating above the boiling point of water and the alcohol enables the continuous removal of the formed water causing a shift in equilibrium towards the esterification. On the other hand, it allows operating in the presence of a very low alcohol concentration to prevent the degradation of the catalyst by the rapid release of the clay acidity. The performance of the semi-continuous reactor was also demonstrated by the possibility to esterify with hydrated alcohol without any decrease of ester yield compared to anhydrous alcohol.

\section{References and Notes}

1. Chemat, F.; Poux, M.; Galema, S.A. Esterification of stearic acid by isomeric forms of butanol in a microwave oven under homogeneous and heterogeneous reaction conditions. J. Chem. Soc., Perkin Trans. 2 1997, 2371-2374.

2. Liu, Y.; Lotero, E.; Goodwin, J.G. Effect of carbon chain length on esterification of carboxylic acids with methanol using acid catalysis. J. Catal. 2006, 243, 221-228.

3. Ma, F.; Hanna, M.A. Biodiesel production: A review. Bioresour. Technol. 1999, 70, 1-15.

4. Srivastava, A.; Prasad, R. Triglycerides-based diesel fuels. Renewable Sustainable Energ. Rev. 2000, 4, 111-133.

5. Ravindra Reddy, C.; Lyengar, P.; Nagendrappa, G.; Jai Prakash, B.S. Esterification of succinic anhydride to di-(p-cresyl) succinate over $\mathrm{Mn}^{+}$-montmorillonite clay catalysts. J. Mol. Catal. A 2005, 229, 31-37.

6. Chen, X.; Xu, Z.; Okuhara, T. Liquid phase esterification of acrylic acid with 1-butanol catalysed by solid acid catalysts. Appl. Catal. A: Gen. 1999, 180, 261-269.

7. Yadav, G.D.; Thagathar, M.B. Esterification of maleic acid with ethanol over cation-exchange resin catalyst. React. Funct. Polym. 2002, 52, 99-110.

8. Zang, Y.; Ma, L.; Yang, J. Kinitics of esterification of lactic acid with ethanol catalyzed by cationexchange resins. React. Funct. Polym. 2004, 61, 101-114.

9. Kirumakki, S.R.; Nagaraju, N.; Chary, K.V.R. Esterification of alcohols with acetic acid over Zeolites Hß, HY and HZSM5. Appl. Catal. A: Gen. 2006, 299, 185-192.

10. Kirumakki, S.R.; Nagaraju, N.; Narayanan, S.A. Comparative esterification of benzyl alcohol with acetic acid over zeolites H $\beta$, HY and HZSM5. Appl. Catal. A: Gen. 2004, 273, 1-9.

11. Wu, K.; Chen, Y. An efficient two-phase reaction of ethyl acetate production in modified ZSM-5 zeolites. Appl. Catal. A: Gen. 2004, 257, 33-42.

12. Chu, W. Yang, X.; Ye, X.; Wu, Y. Vapor phase esterification catalyzed by immobilized dodecatungstosilicic acid $\left(\mathrm{SiW}_{12}\right)$ on activated carbon. Appl. Catal. A: Gen 1996, 145, 125-140. 
13. Sepulveda, J.H.; Yori, J.C.; Vera, C.R. Repeated use of supported $\mathrm{H}_{3} \mathrm{PW}_{12} \mathrm{O}_{40}$ catalysts in the liquid phase esterification of acetic acid with butanol. Appl. Catal. A: Gen 2005, 288, 18-24.

14. Jermy, B.R.; Pandurangan, A. Catalytic application of Al-MCM-41 in the esterification of acetic acid with various alcohols. Appl. Catal. A: Gen 2005, 288, 25-33.

15. Kirumakki, S.R.; Nagaraju, N.; Chary, K.V.R.; Narayanan, S. Kinetics of esterification of aromatic carboxylic acids over zeolites H $\beta$ and HZSM5 using dimethyl carbonate. Appl. Catal. A: Gen 2003, 248, 161-167.

16. Ravindra Reddy, C.; Lyengar, P.; Nagendrappa, G.; Jai Prakash, B.S. Esterification of dicarboxylic acids to diesters over $\mathrm{Mn}^{+}$-montmorillonite clay catalysts. Catal. Lett. 2005, 101, 87-91.

17. Sabu, K.R.; Sukurmar, R.; Rekha, R.; Lalithambika, M. A comparative study on $\mathrm{H}_{2} \mathrm{SO}_{4}, \mathrm{HNO}_{3}$ and $\mathrm{HClO}_{4}$ treated metakaolinite of a natural kaolinite as Friedel-Crafts alkylation catalyst. Catal. Today 1999, 49, 321-326.

18. Brown, D.R.; Rodhes, C.N. Brönsted and Lewis acid catalysis with ion-exchanged clays. Catal. Lett. 1997, 45, 35-40.

19. Mokays, R.; Jones, W. Pillared clays and pillared acid-activated clays: a comparative study of physical, acidic, and catalytic properties. J. Catal. 1995, 153, 76-85.

20. Shah, N.F.; Sharma, M.M. Dimerization of isoamylene: Ion exchange resin and acid-treated clay as catalysts. React. Polym. 1993, 19, 181-90.

21. Perissinotto, M.; Lenarda, M.; Storaro, L.; Ganzerla, R. Solid acid catalysts from clays: Acid leached metakaolin as isopropanol dehydratation and 1-butene isomerisation catalyst. J. Mol. Catal. A 1997, 121, 103-109.

22. Shah, N.F.; Bhagwat, M.S.; Sharma, M.S. Cross-dimerization of methylstyrene with isoamylene and aldol condensation of cyclohexanone using a cation-exchange resin and acid-treated clay catalysts. React. Polym. 1994, 22, 19-34.

23. Silva, F.C.; Souza, M.C.B.V.; Ferreira, V.F.; Sabino, S.J.; Antunes, O.A.C. Natural clays as efficient catalysts for obtaining chiral-enamino esters, Catal. Commun. 2004, 5, 151-155.

24. Vodnár, J.; Farkas, J.; Békássy, S. Catalytic decomposition of 1,4-diisopropylbenzene dihydroperoxide on montmorillonite-type catalysts. Appl. Catal. A: Gen. 2001, 208, 329-334.

25. Zhou, M.; Gilot, B.; Domenech, S. Modélisation d'un réacteur d'estérification Partie 1 estérification de l'acide oléique par le méthanol. Détermination des données thermodynamiques et cinétique. Entropie 1984, 120, 3-10.

26. Zhou, M.; Gilot, B.; Domenech, S. Modélisation d'un réacteur d'estérification Partie 2 modelisation d'un réacteur d'estérification à fonctionnement semi-continu. Entropie 1984, 120, 11-18.

27. Frikha, M.H.; Benzina, M.; Gabsi, S. Estérification des acides gras libres de l'huile de grignon d'olive par l'éthanol à une température supérieure à celle de l'azéotrope. Influence des phénomènes diffusionnels sur la cinétique de la réaction. Entropie 1991, 191, 41-46.

28. Carmo, A.C.; De Souza, L.K.C.; Da Costa, C.E.F.; Longo E.; Zamian, J.R.; Da Rocha Filho, G.N. Production of biodiesel by esterification of palmitic acid over mesoporous aluminosilicate Al-MCM-41. Fuel 2009, 88, 461-468. 
29. Pushpaletha, P.; Rugmini Lalithambika, S. Correlation between surface properties and catalytic activity of clay catalysts. Appl. Clay Sci. 2005, 30, 141-153.

30. Hanh, H.D.; Dong, N.T.; Okitsu, K.; Nishimura, R.; Maeda, Y. Biodiesel production by esterification of oleic acid with short-chain alcohols under ultrasonic irradiation condition. Renew. Energy 2009, 34, 780-783.

31. Georgogianni, K.G.; Katsoulidis, A.P.; Pomonis, P.J.; Kontominas, M.G. Transesterification of soybean frying oil to biodiesel using heterogeneous catalysts. Fuel Process. Technol. 2009, 90, 671-676.

32. Caetano, C.S.; Guerreiro, L.; Fonseca, I.M.; Ramos, A.M.; Vital, J.; Castanheiro, J.E. Esterification of fatty acids to biodiesel over polymers with sulfonic acid groups. Appl. Catal. A: Gen. 2009, 359, 41-46.

33. Marchetti, J.M.; Errazu, A.F. Comparison of different heterogeneous catalysts and different alcohols for the esterification reaction of oleic acid. Fuel 2008, 87, 3477-3480.

34. Lotero, E.; Liu, Y.; Lopez, D.E.; Suwannakarn, K.; Bruce, D.A.; Goodwin, J.G. Synthesis of Biodiesel via Acid Catalysis. Ind. Eng. Chem. Res. 2005, 44, 5353-5363.

(C) 2009 by the authors; licensee Molecular Diversity Preservation International, Basel, Switzerland. This article is an open-access article distributed under the terms and conditions of the Creative Commons Attribution license (http://creativecommons.org/licenses/by/3.0/). 